\title{
Characteristics and differentiated mechanism of vascular endothelial cells-like derived from epithelial ovarian cancer cells induced by hypoxia
}

\author{
LIANG-QING YAO $^{1}$, YOU-JI FENG ${ }^{1}$, JING-XIN DING ${ }^{1}$, HUI-MING JING ${ }^{2}$, CONG-JIAN XU ${ }^{1}$, \\ SI-FENG CHEN ${ }^{2,3}$, MING SU ${ }^{1}$ and LIANG-HUA YIN ${ }^{2}$

\begin{abstract}
${ }^{1}$ Department of Gynecologic Oncology, Obstetrics and Gynecology Hospital, Fudan University, Shanghai 200011;
${ }^{2}$ Department of Pathophysiology and Molecular Angiogenesis Laboratory, Fudan University, Shanghai 200032,

P.R. China; ${ }^{3}$ Department of Medicine, University of Alabama at Birmingham, Birmingham, AL 35294, USA
\end{abstract}

Received December 11, 2006; Accepted February 1, 2007

\begin{abstract}
A few highly aggressive and malignant tumor cells could acquire identities by turning on genes expressed by endothelial cells and recruit blood vessels to sustain tumor growth. Hypoxia was reported recently to play an essential role in these events. These 'plastic' tumor-cell phenotypes and the exact mechanism driving transendothelial differentiation by hypoxia-inducible factor (HIF)- $1 \alpha$ is unclear. In this study, epithelial ovarian carcinoma cells were exposed to hypoxia and the tumor cells were transformed into endothelial cellslike (ECs-like). Typical endothelial features such as cell markers and uptaking of acetylated low density lipoprotein were identified constantly. Small interference RNA was used to block the expression of HIF-1 $\alpha$. Analysis revealed that hypoxia promotes transendothelial differentiation through stimulating HIF-1-dependent transcriptional expression of vascular endothelial growth factor (VEGF), VEGF receptor-2 (Flk-1) and P53, and through decreasing HIF-1-independent transcriptional expression of Cyclin D1. These results demonstrate that ECs-like derived from epithelial ovarian cancer cells are similar to endothelial progenitor cells rather than endothelial cells. HIF- $1 \alpha$ is crucial but not unique in alternation of tumor cells towards ECs-like.
\end{abstract}

\section{Introduction}

Tumor angiogenesis is of critical importance in the development and metastatic spread of tumors (1). It has been taken for granted that all intratumoral vascular channels are formed and lined by endothelial cells (ECs) (2). A novel microcirculation

Correspondence to: Professor You-Ji Feng, Department of Gynecologic Oncology, Obstetrics and Gynecology Hospital, Fudan University, Shanghai 200011, P.R. China

E-mail: fengyouji@126.com

Key words: epithelial ovarian cancer cells, trans-differentiation, vascular endothelial cells-like, hypoxia-inducible factor- $1 \alpha$ was recently described in uveal melanomas by which aggressive tumor cells generate non-EC-lined channels delimited by extracellular matrix and is independent of angiogenesis. 'Vasculogenic mimicry' was a name assigned to this process (3). There was preliminary evidence that this phenomenon occurs in some highly aggressive tumors including prostate tumor, lung carcinoma, breast cancer and glioblastoma cancer (4-6). Tumor cells are provided with direct access to the bloodstream by the new type of blood vessels and tend to spread aggressively. Some current antiangiogenesis efforts might have overlooked the blood vessels made by the actual cancer cells. Patients with vasculogenic mimicry were very likely to develop metastases with shorter life expectancy (7). The finding calls for reappraisal of the current assumption that endothelial cell-mediated angiogenesis is the only mechanism underlying or responsible for tumor growth and metastasis and poses challenges to antiangiogenesis strategies of cancer treatment. Microarray analysis found that cancer cells acquired identities by activating genes expressed by key ECs (8). These observations prompt further investigation into the potential relevance of a 'plastic' tumor-cell phenotype. Identifying characteristics of these channel-lined cells will provide new perspectives to combat the tumor vessel formation.

Hypoxia, one of the essential features of tumor microenvironment, is associated with neoplastic malignant progression and poor prognosis. Hypoxia can induce tumor angiogenesis, drive clonal selection, change expression of suppressor genes or oncogenes, contribute to resistance to chemo- and radio-therapies as well as lead to differentiation (9-16). Jögi et al demonstrated that human neuroblastoma cells grown under hypoxic conditions lose their neuronal and develop a neural crest-like phenotype (17). Hypoxia also induces dedifferentiation and drives promotion of the aggressive phenotype in ductal breast cancer (18). Hypoxia is known to be a critical mediator of tumor angiogenesis through hypoxia-inducible factor (HIF)-1 $\alpha$ (9). Studies have recently shown that hypoxia is of great importance in the development of vasculogenic mimicry (19-21), but the exact mechanism by which HIF-1 $\alpha$ acts in differentiation of aggressive tumor cells towards endothelial cells-like (ECs-like) that are involved in vasculogenic mimicry remains to be elucidated. 
Ovarian carcinoma mainly consisting of epithelial cancer is the leading cause of death from gynecologic cancers. Vasculogenic mimicry has been described in ovarian cancer previously $(22,23)$. Based on the assumption that the microenvironment has powerful influence in determination of cell differentiation $(24,25)$, we created a supportive environment with low oxygen tension on appropriate scaffolds to direct differentiation of epithelial ovarian cancer cells SKOV-3 and ES-2 into ECs-like. Typical endothelial features such as cell markers, microstructures and uptaking of acetylated low density lipoprotein (acLDL) were identified by immunofluorescence, RT-PCR and electron microscopy. Small interference RNA (siRNA) was used to block the expression of HIF-1 $\alpha$. After laser capture microdissection, the role of HIF-1 $\alpha$ in tumor cell transendothelial differentiation was analyzed by quantitative real-time RT-PCR. The present study suggested that the differentiated ECs-like associated with tumor stem cells possess some typical EC characteristics. HIF-1 $\alpha$-modulated differentiation is an important mechanism in transendothelial differentiation of ovarian tumor cells.

\section{Materials and methods}

Three-dimensional cultures and hypoxic treatment. Human epithelial ovarian carcinoma cell lines SKOV-3 and ES-2 were purchased from American Type Culture Collection (ATCC, Manassas, VA), and were maintained in McCoy's 5a. Thirty microliters of Matrigel (B\&D, Bedford, MA) were dropped onto each glass coverslip in a 12-well culture plate and polymerized for $1 \mathrm{~h}$ at room temperature, then $30 \mathrm{~min}$ at $37^{\circ} \mathrm{C}$ in a humidified $5 \% \mathrm{CO}_{2}$ incubator, as described previously (22). Tumor cells $\left(1 \times 10^{4}\right)$ were seeded onto the three-dimensional gel. The medium with $15 \%$ FBS was changed every $36 \mathrm{~h}$. Hypoxic condition was created by flushing $5 \% \mathrm{CO}_{2}$ and $95 \% \mathrm{~N}_{2}$ through a modified chamber (Mitsubishi, Japan), until $\mathrm{O}_{2}$ concentration was reduced to $1 \%$, measured with a Mini oxygen meter. The culture system was then sealed and incubated at $37^{\circ} \mathrm{C}(14)$.

Small interference RNA. To demonstrate the specificity of siRNA against HIF-1 $\alpha$, the following oligonucleotides were used: position 127, 5'-CAGTTGCCACTTCCACATA-3'. Oligonucleotides were synthesized and ligated into pRNATU6.1/Neo vector by Kanchen Biologic Technology Co. (Shanghai, P.R. China) according to the manufacturer's directions. A total of $2 \times 10^{5}$ cells were seeded into each well of a 24-well plate without gentamicin. On the following day (when the cells were $85-90 \%$ confluent), the culture medium was aspirated and cells were transfected with $0.8 \mu \mathrm{g}$ of the silencing plasmid pRNAT-U6.1/Neo and $2 \mu \mathrm{l}$ Lipofectamine 2000 (Invitrogen, Carlsbad, CA). As control, cells were exposed to Lipofectamine 2000 without siRNA encoding plasmids, and oligonucleotides which do not have any target region in human genes served as negative control. Twenty-four hours after transfection, the resultant transfection efficiency using constructs expressing GFP assessed by fluorescence microscopy was $\sim 65 \%$ (ES-2) and $\sim 80 \%$ (SKOV-3) respectively. Stable transfected cells were selected by $0.4 \mathrm{mg} / \mathrm{ml}$ (SKOV-3) or $0.5 \mathrm{mg} / \mathrm{ml}$ (ES-2) G418 (Merck, Darmstadt, Germany) after approximately 2 weeks. The efficiency of HIF-1 $\alpha$ silencing was analyzed by Western blotting.

Light and electron microscopy. Any extra-cellularly derived structures were directly examined by light microscopy (Leica, Wetzlar, Germany), and photographed with digital camera. For scanning electron microscopy and transmission electron microscopy, tissue cultures were fixed in cold $2.5 \%$ glutaraldehyde in $0.1 \mathrm{~mol} / \mathrm{l}$ of sodium cacodylate buffer and postfixed in osmium. Specimens were then either embedded, sectioned, and stained by routine procedures for Philips CM 120 transmission electron microscopy, or critically pointdried, and sputter-coated with gold for Hitachi S-520 scanning electron microscopy, as previously described (26). Semithin sections were studied by light microscopy and ECs-like were spotted when tissues were sectioned for transmission electron microscopy.

Immunofluorescence assay. After the cells were allowed to grow channels on glass coverslips, cultures were washed with PBS and fixed with $3 \%$ paraformaldehyde at $4{ }^{\circ} \mathrm{C}$ for 5 min, subsequently permeabilized with $1 \%$ Triton $\mathrm{X}-100$ for 10 min and washed with PBS. Cultures were incubated with primary monoclonal antibodies (mouse anti-human B blood type in SKOV-3 cultures, Zymed, South San Francisco, CA; mouse anti-human $\mathrm{P}$ glycoprotein in ES-2 cultures, Santa Cruz, Santa Cruz, CA, respectively) and washed with PBS, then incubated with TRITC-labeled goat anti-mouse secondary antibody (Friendship Biotechnology, Shanghai, P.R. China), respectively, for $90 \mathrm{~min}$ at $37^{\circ} \mathrm{C}$ in humidified blind incubator. After completing the first staining, cultures were incubated with primary polyclonal antibodies including rabbit antihuman vWF antibody (NeoMarkers, Fremont, CA), rabbit anti-human CD34 antibody (Santa Cruz), rabbit anti-human AC133 antibody (Novus Biologicals, Littleton, CO), and rabbit anti-human Flk-1 antibody (Neomarkers) respectively, and then treated with FITC-labeled mouse anti-rabbit secondary antibody (Friendship) to complete the second staining according to the first staining process described above. The images were obtained by fluorescence microscopy (Leica). All negative controls were processed by omitting the primary antibody.

Uptake of acLDL. Twenty $\mu \mathrm{g} / \mathrm{ml}$ DiL-acLDL (Molecular Probes, Eugene, OR) was added to media, and incubated with cultured cells on gel for $4 \mathrm{~h}$ at $37^{\circ} \mathrm{C}$ in a humidified incubator on the 8th day, and then washed twice with PBS. Human umbilical vein endothelial cells and SKOV-3 or ES-2 cells were used as a positive and negative reference, respectively. The images were obtained using a fluorescent microscope.

Laser capture microdissection. Fifteen mocroliters of Matrigel were mounted on ethylene vinyl acelate (EVA) membrane (Leica) with frame instead of coverslip in 9-cm dishes and treated to establish three-dimensional culture as described above. The density of tumor cells seeded onto gel was adjusted to $1 \times 10^{5}$. After 7-day culture, samples with EVA member were washed with PBS-DEPC and air-dried, channels formed by endothelial cells-like were selected by microscopic visualization and laser microdissected with an LCM system (Leica). 
Approximately 1,500-2,000 ECs-like were laser-captured from each EVA member. The cells were immersed in digestion buffer for reverse transcription polymerase chain reaction (RT-PCR), or quantitative real-time RT-PCR.

$R T-P C R$ and quantitative real-time RT-PCR. Total RNA was extracted from $2 \times 10^{4}$ ECs-like using TRIzol reagent (Invitrogen). Aliquots of RNA were reverse transcribed to cDNA using a Superscribe First-Strand synthesis system (Invitrogen). Aliquots of cDNA were used as template for PCR to verify expression of Flk-1, vWF, CD34, AC133, Blood type $\mathrm{B}$ or $\mathrm{P}$ glycoprotein at transcription level. Thermocycling conditions were $45 \mathrm{sec}$ at $95^{\circ} \mathrm{C}, 30 \mathrm{sec}$ at $58^{\circ} \mathrm{C}$, and $45 \mathrm{sec}$ at $72^{\circ} \mathrm{C}$ for 40 cycles, and a final extension of $72^{\circ} \mathrm{C}$ for $7 \mathrm{~min}$. The PCR reactions were then visualized on a $1.5 \%$ agarose gel containing $5 \mu \mathrm{g} / \mathrm{ml}$ of ethidium bromide after electrophoresis. The primers were as follows: Flk-1 (140 bp): 5'-ACAGTGGTATGGTTCTTGCCTCA-3', 5'-GTAGCCGC TTGTCTGGTTTGA-3'; vWF (159 bp): 5'-TCCACCGAA GCACCATCTACC-3', 5'-GAACGTAAGTGAAGCCCGA CC-3'; CD34 (150 bp): 5'-GCGCTTTGCTTGCTGAGTTT-3', 5'-TCCAAGGGTACTAGGTGTTGTAG-3'; AC133 (97 bp): 5'-CATCCACAGATGCTCCTAAGGC-3', 5'-AAGAGAAT GCCAATGGGTCCA-3'; Blood type B (189 bp): 5'-CAATG CACACTTCAACCTCTT-3', 5'-TCAGTCGGCGAATACT GTAAG-3'; P glycoprotein (174 bp): 5'-CACATGACTTT CGGCGGATGA-3', 5'-GCTGCGTTATTGGCTTCACC-3'; B-actin (211 bp): 5'-CCTGTACGCCAACACAGTGC-3', 5'-ATACTCCTGCTTGCTG ATCC-3'.

Real-time PCR analysis was performed to quantify mRNA expression of VEGF, Flk-1, Cyclin D1, P53, and V-src on a Rotor-Gene3000 PCR system (Corbett, Australia) using the SYBR-Green PCR Master mix (Qiagen, Hilden, Germany). The PCR reaction consisted of $12.5 \mu 1$ of SYBR-Green PCR Master mix, $1 \mu 1$ of forward and reverse primers, and $2.0 \mu 1$ of 1:10-diluted template cDNA in a total volume of $25 \mu 1$. Amplification was initiated at $50^{\circ} \mathrm{C}$ for $2 \mathrm{~min}, 95^{\circ} \mathrm{C}$ for $70 \mathrm{sec}$, followed by 40 rounds of $95^{\circ} \mathrm{C}$ for $20 \mathrm{sec}, 58^{\circ} \mathrm{C}$ for $20 \mathrm{sec}$, and $72^{\circ} \mathrm{C}$ for $30 \mathrm{sec}$. To verify that the used primer pair produced only a single product, a dissociation protocol was added after thermocycling, determining dissociation of the PCR products. The assay included a no-template control, a standard curve of four serial dilution points (in steps of 10-fold) of a cDNA mixture, and each of the tested cDNAs. All data were controlled using Rotor-Gene software (version 6.0) for quantity of RNA input by performing measurements on an endogenous reference gene ( $\beta$-actin) from the same reverse transcription reaction. Data are means from three separate experiments. The primers are as follows: VEGF (166 bp): 5'-TCACCAAGGCCAGCACATAG-3', 5'-GGGAACGC TCCAGGACTTAT-3'; Flk-1 (140 bp): 5'-ACAGTGGTA TGGTTCTTGCCTCA-3', 5'-GTAGCCGCTTGTCTGG TTTGA-3'; Cyclin D1 (171 bp): 5'-GATGCCAACCTCC TCAACGAC-3', 5'-CTCCTCGCACTTCTGTTCCTC-3'; P53 (298 bp): 5'-GCTGCTCAGATAGCGATGGTC-3', 5'CTCCCAGGACAGGCACAAACA-3'; V-src (196 bp): 5'CACTCGCTCAGCACAGGACAG3', 5'-AGAGGCAGT AGGCACCTTTCG-3'; ß-actin (211 bp): 5'-CCTGTACG CCAACACAGTGC-3', 5'-ATACTCCTGCTTGCTGAT CC-3'.
All human-specific primers were designed using Primer3 web software (Whitehead Institute, Cambridge, MA) and were synthesized by Sangon Biological Engineering Technology and Service Co., Ltd. (Shanghai, P.R. China).

Western blot assay. Total protein was extracted from all of transfected or non-transfected cells using Mammalian protein extraction reagent (Pierce, Rockford, IL), and an equal amount of protein from each cell line was loaded per lane and separated on a $7.5 \%$ SDS-Tris glycine PAGE gel. Gels were electroblotted onto nitrocellulose membranes (Novex, San Diego, CA) and blocked overnight by incubating with $1 \mathrm{X}$ Trisbuffered saline containing $0.1 \%$ Tween and 5\% non-fat milk. Membranes were probed with HIF-1 $\alpha$ (Santa Cruz) or specificGAPDH antibody (Kangchen). The membranes were then incubated for $1 \mathrm{~h}$ at room temperature with horseradish peroxidase-conjugated secondary antibody. Labeled bands from washed blots were detected by ECL. Protein expression was semi-quantified using a Tiannen imager and analysis system (Shanghai, P.R. China).

Statistical analysis. ANOVA analysis or paired-samples t-test were performed to identify differences, using SPSS11.5 statistical software (Lead, US). Statistical significance was assumed at $\mathrm{P}<0.05, \mathrm{P}$-values presented are two-sided.

\section{Results}

Hypoxia promotes dedifferentiation in ovarian cancer cells towards ECs-like. Ovarian cancer cells were seeded and expanded on three dimensional gel exposed to $1 \%$ oxygen. In the first three days, a few tumor cells initiated to extend and reshape, gradually developed ECs-like and connected with each other, eventually forming network structures and channels by day 7 (Fig. 1A-D). Scanning electron microscopic exam demonstrated hollow tubes with diameter ranging from $8 \mu \mathrm{m}$ to $20 \mu \mathrm{m}$ (Fig. $1 \mathrm{G}$ and $\mathrm{H}$ ). Tumor cells transfected with siRNAHIF- $1 \alpha$ also extended, reshaped and became arc or strip-like appearances, but these cells did not form any kinds of structures or channels even over 14 days until cultures ceased (Fig. 1E and F). On the contrary, cells only grew attached to gel under normoxic conditions $\left(21 \% \mathrm{O}_{2}\right)$.

Characteristics of ECs-like derived from ovarian cancer cells. Antigen expression was of blood group B in SKOV-3 and P glycoprotein in ES-2 according to ATCC description. Immunofluorescence assay demonstrated that blood type $\mathrm{B}$ is expressed in SKOV-3 and $\mathrm{P}$ glycoprotein in ES-2, and EC-related markers Flk-1, AC133, CD34 and vWF are not expressed in two types of untreated ovarian cancer cells. After hypoxia promoted induction on the three-dimensional gel, ECs-like derived from SKOV-3 expressed Flk-1, AC133 and vWF except for CD34. Cells derived from ES-2 expressed Flk-1 and CD34 (Fig. 2A). ECs-like cells derived from both SKOV-3 and ES-2 expressed blood type B and P glycoprotein simultaneously under hypoxia conditions. However, tumor cells cultured under normoxic conditions or treated by HIF-1 siRNA did not express any of the markers mentioned above. We confirmed the results using RT-PCR at transcription level after ECs-like were isolated by LCM (Fig. 2B). 
SKOV-3
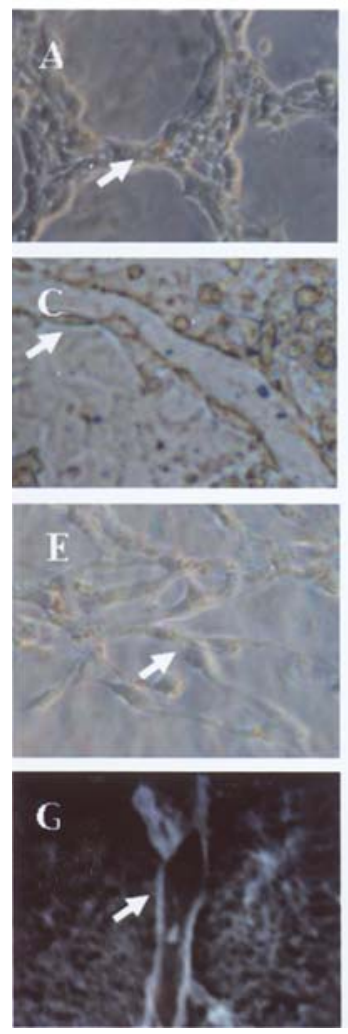

ES-2
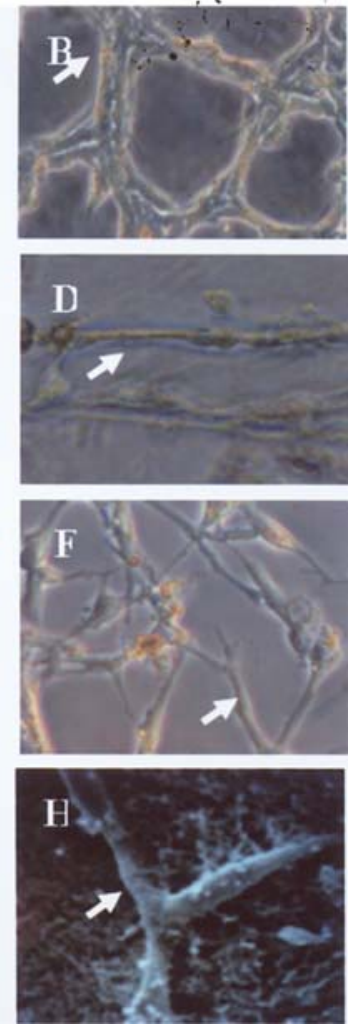

Figure 1. Hypoxia $\left(1 \% \mathrm{O}_{2}\right)$ induced ovarian cancer cell transendothelial differentiation and channel formation on three-dimensional gel by 7 days. A-D, tubular network and channel formation under light microscope, arrowheads point to ECs-like derived from tumor cells. E and F, tumor cells transfected with siRNA $\mathrm{HIF-1 \alpha}_{1}$ showing arc or strip-like and no channel formation. $\mathrm{G}$ and $\mathrm{H}$, tubular profiles with hollows lined by ECs-like under scanning electron microscope. Representative changes were chosen for photography (original magnification x200, A and B; x400, C-F; x1500, G and $\mathrm{H})$.

To further define the microstructure of ECs-like, transmission electron microscopy was performed. Vacuoles and occasional granules with a single membrane which was considered as a cross section of Weibel-palade body in cytoplasm, and micro-villi outstanding of the cell surface were found while nuclei extended accordingly in ECs-like (Fig. 3A and B). These changes were not observed in tumor cells.

It is well established that EC is the main cell type responsible for acLDL uptake (27), ECs-like's capability of acLDL uptake was explored in the present study as well. Experiments showed that distribution of DiL-labeled acLDL existed in a fraction of ECs-like derived from ES-2 lining along channels (Fig. 3C and D), but not in ECs-like from SKOV-3 and other tumor cells.

Role of HIF-la in transendothelial differentiation. Analysis of HIF- $1 \alpha$ protein expression showed that HIF- $1 \alpha$ is hardly expressed in SKOV-3 and ES-2 but highly expressed by 9.7and 3.8-fold, respectively, in ECs-like induced by hypoxia on three-dimensional gel $(\mathrm{P}<0.01$; Fig. $4 \mathrm{~A}$ and $\mathrm{B})$. Channels were inhibited consequently in vitro while HIF-1 $\alpha$ were mostly down-regulated ( $75 \%$ in SKOV-3 and $\sim 68 \%$ in ES-2, $\mathrm{P}<0.01$; Fig. 4A and B) by HIF- $1 \alpha$ siRNA under hypoxic conditions.
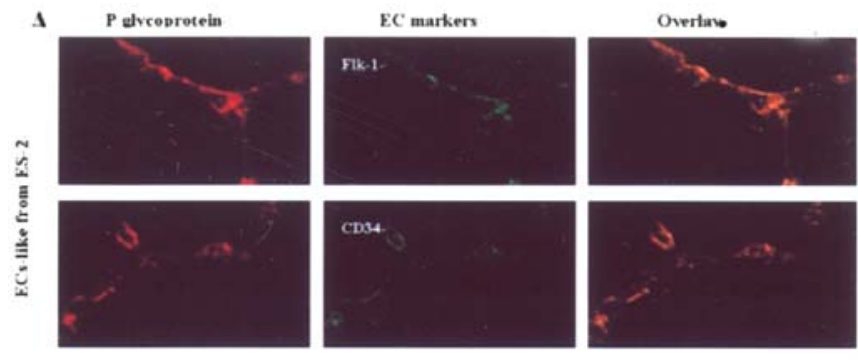

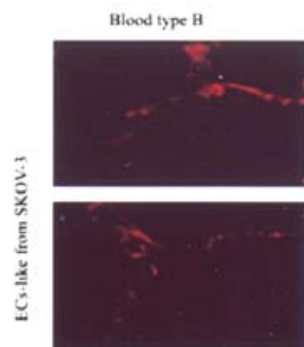

EC markers

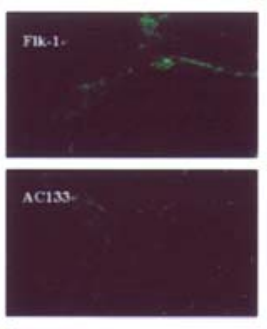

nwF-
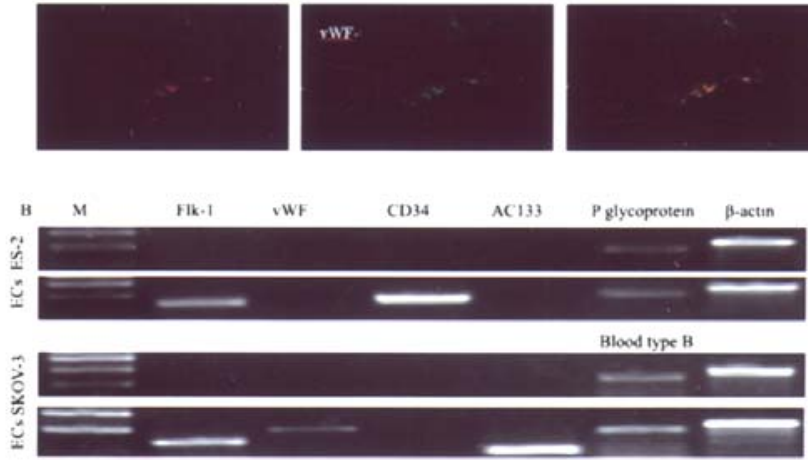

Figure 2. Immunofluorescence and RT-PCR analysis of cellular markers of ECs-like derived from ovarian cancer cells. A, lane 1 (red) shows immunofluorescence staining of P glycoprotein (ES-2) and blood type B (SKOV-3); lane 2 (green) shows immunofluorescence staining of markers associated with EC including Flk-1, CD34, AC133 and vWF. Staining intensity varied among three separate experiments. B, ECs-like were defined by RT-PCR for markers compared with initiated tumor cells.
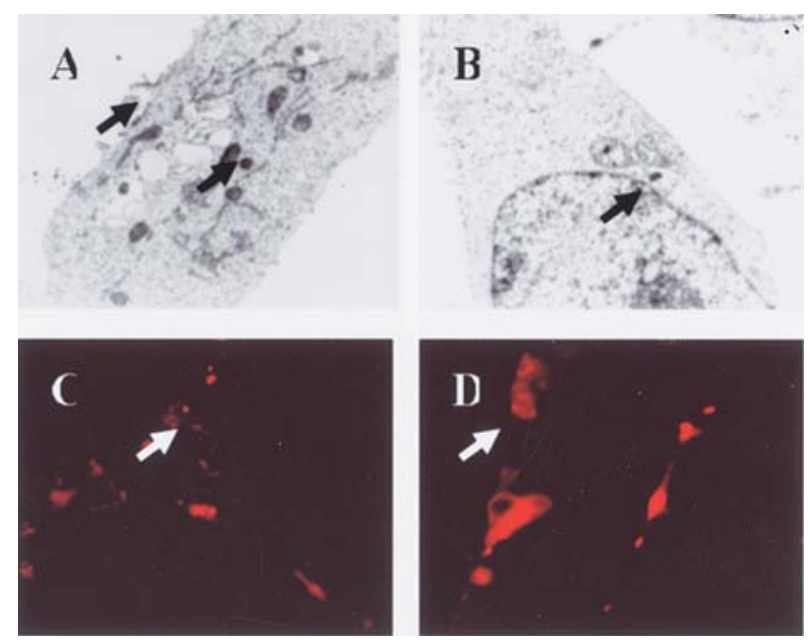

Figure 3. Ultrastructural characteristics under transmission electron microscope and capability of acLDL uptake under fluorescent microscope of ECs-like. $\mathrm{A}$ and $\mathrm{B}$, micro-villi and Weibel-palade body indicated by arrowheads were found in ECs-like from SKOV-3 (A) and ES-2 (B) while cells extended accordingly. Poor Weibel-Palade body morphology was considered as cross section. C and D, distribution of Dil-labeled acLDL existed in fraction of ECs-like derived from ES-2 lining along channels indicated by arrowheads (original magnification x15000, A and B; x400, C and D). 
A

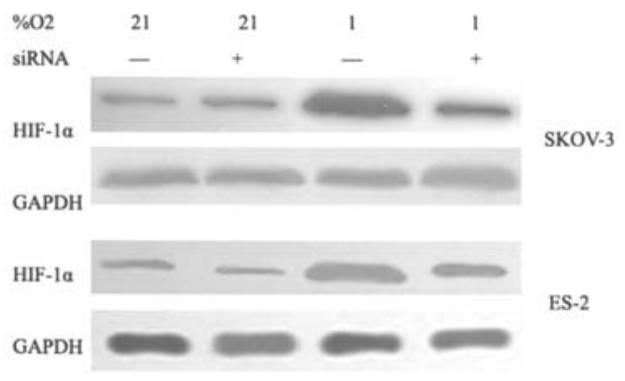

C.

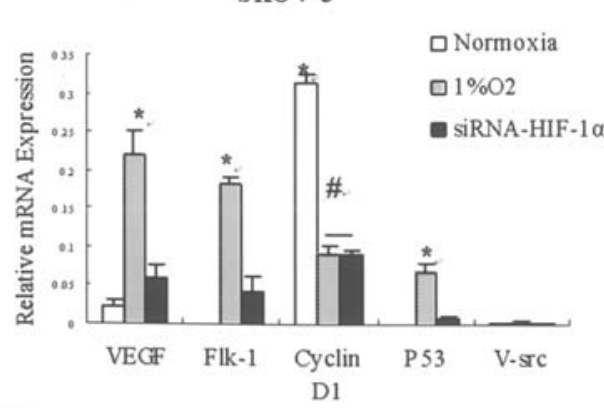

B siRNA-Mediated Down-Regulation of HIF-1a Proteins

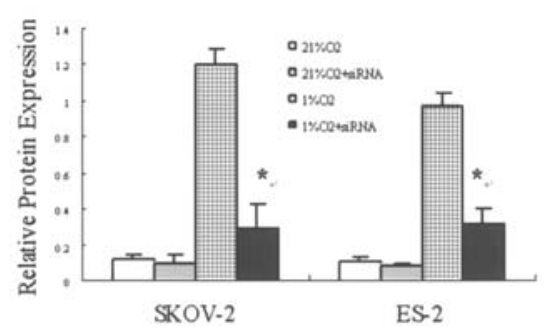

D. DS-2

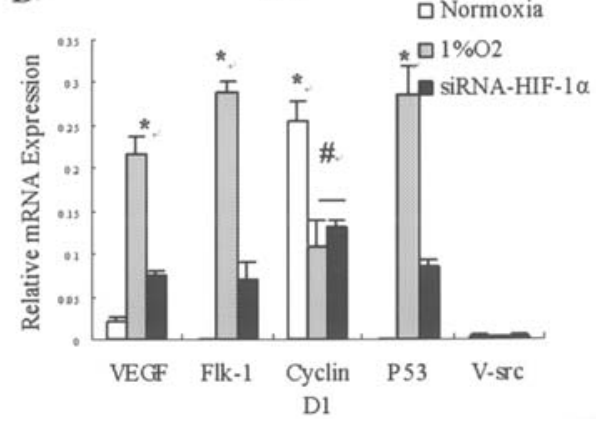

Figure 4. Effect of siRNA-HIF-1 $\alpha$ and role of HIF- $1 \alpha$ in transendothelial differentiation. A and B, Western blot analysis of HIF-1 $\alpha$ proteins at the 8th day, siRNA mediated down-regulation of HIF- $1 \alpha\left({ }^{*} \mathrm{P}<0.05\right)$. C and D, analysis of real-time RT-PCR at the 8th day revealed that hypoxia increased mRNA expression of VEGF, Flk-1 and P53, and decreased expression of Cyclin D1 during transendothelial differentiation, these changes were inhibited effectively by RNA interference of HIF-1 $\alpha$, but no significant difference of Cyclin D1 was shown with siRNA-mediated inactivation of HIF-1 $\alpha$. No cells expressed V-src mRNA under all conditions. Data shown are the mean results $\pm \mathrm{SD}$ of three separate experiments $\left({ }^{*} \mathrm{P}<0.01 ;{ }^{*} \mathrm{P}>0.05\right)$.

In an attempt to gain specific insight into the mechanisms of hypoxia induction, we further examined hypoxia response gene mRNA levels including VEGF, Flk-1, Cyclin D1, P53 and V-src of ECs-like isolated by LCM while siRNA was used to inactivate HIF-1 $\alpha$. Hypoxia strongly promoted VEGF and Flk-1 mRNA expression in ECs-like when compared to two cancer cells in vitro (9.2-10.2- and 18.3-28.8-fold, respectively, all $\mathrm{P}<0.01$; Fig. $4 \mathrm{C}$ and $\mathrm{D})$. The effect was inhibited effectively by HIF- $1 \alpha$ siRNA under hypoxia. The inhibition of VEGF was $\sim 72 \%$ in SKOV-3 and $\sim 65 \%$ in ES-2, and of Flk-1 was $\sim 77 \%$ in SKOV-3 and $~ 76 \%$ in ES-2 ( $\mathrm{P}<0.01$; Fig. 4C and D). Analysis revealed that mRNA expression of Cyclin D1 was high in SKOV-3 and ES-2, and decreased to 29.4-42.2\% of ECs-like ( $\mathrm{P}<0.01$; Fig. $4 \mathrm{C}$ and $\mathrm{D})$, this change was not recovered by inhibition of HIF- $1 \alpha$ expression induced by hypoxia (Fig. 4C and D). P53 showed significantly high expression in both ECs-like while it was not expressed in SKOV-3 and ES-2 ( $\mathrm{P}<0.01$; Fig. $4 \mathrm{C}$ and $\mathrm{D})$. Inhibition of HIF-1 $\alpha$ expression was sufficient to block hypoxia-induced P53 mRNA expression ( $\sim 88 \%$ in SKOV-3 and $\sim 70 \%$ in ES-2, $\mathrm{P}<0.01$; Fig. $4 \mathrm{C}$ and $\mathrm{D})$. Our data further showed that no cells expressed $\mathrm{V}$-src mRNA under normoxic or hypoxic conditions.

\section{Discussion}

The evidence shown previously demonstrated the powerful influence of the microenvironment on the transendothelial differentiation of aggressive melanoma cells (24). It is known that polymer scaffolds under compressive stress can promote cell differentiation (25). Hypoxia is a major physiologic stimulus for angiogenesis in oncology (9). The present study challenged ovarian cancer cells to differentiate into ECs-like and form channels using an environment with low oxygen tension on scaffolds. Ovarian cancer cells were successfully engaged in network formation surrounding spheroids of tumor cells in three-dimensional culture (22), these quiescent cellular spheroids are analogous to those regions within tumors, resulting in hypoxia $(28,29)$. This strongly implies that the effect of hypoxia in the process can not be excluded. A recent study also found that expression of genes such as laminin $5 \gamma 2$, EphA2, and Tie-1, which were involved in vasculogenic mimicry, were significantly increased in tumor cells under hypoxia (20). The present study demonstrates that hypoxia has a strong induction influence in the event of ECslike differentiation of ovarian cancer cells.

HIF-1 has been identified as a master regulator of the transcriptional response to oxygen deprivation (9). HIF-1 is composed of two subunits, HIF- $1 \alpha$ and HIF-1B. HIF- $1 \alpha$ is the key regulatory component which controls the expression of a variety of genes related tumor biology (17). Channel mimicry by ECs-like was not promoted by interference with the expression of HIF- $1 \alpha$ by siRNA. This demonstrates that HIF-1 modulation is crucial in ovarian cancer cell transdifferentiation towards ECs-like induced by hypoxia. At the molecular level, HIF-1 activates the response of a large assortment of downstream genes to cellular hypoxia. Hypoxic induction of VEGF appears central to tumor angiogenesis (30), VEGF is a potent and specific mitogen for EC and its high affinity receptor Flk-1 is considered to be the dominant 
signaling receptor for EC differentiation in angiogenesis $(31,32)$. The study showed that hypoxia strongly promoted VEGF and Flk-1 mRNA expression in ECs-like different from SKOV-3 and ES-2. Previous study reported that Flt-1 but not Flk-1 is up-regulated by hypoxia at the transcriptional level (31). The present results show that expression of VEGF and Flk-1 can be inhibited while HIF-1 $\alpha$ is silenced. Since VEGF can up-regulate Flk-1 $(33,34)$, the up-regulation of Flk-1 may be related to VEGF expression dependent of HIF-1 $\alpha$. The tumor suppressor P53 has been shown to accumulate under conditions of severe hypoxia, and evidence now links oncogene $\mathrm{V}$-src with angiogenesis stimulated by hypoxia $(35,36)$. This demonstrates that transcriptional activation of P53 via HIF-1 participates in the differentiation of ovarian cancer cells into ECs-like while V-src is silenced.

Cyclin D1 is associated with inactivation of the tumor suppressor pRB, shortened duration of the $G_{1}$ phase and tumor malignant transformation, but the exact manner is still obscure $(37,38)$. This study showed that Cyclin D1 expression of ECs-like decreased significantly after oxygen deprivation. The changes were not recovered by inhibition of HIF-1 $\alpha$ expression. Consistent with the present study, a study showed that high concentrations of HIF-1 $\alpha$ were not associated with the $G_{1}$-phase protein Cyclin D1 in invasive breast cancer (38). The study demonstrates that the decrease of Cyclin D1 contributes to ovarian cancer cell transendothelial differentiation independent of HIF-1, and the exact mechanism requires further investigation.

ECs display some unique characteristics, including the expression of surface markers such as Flk-1, CD34, vWF, platelet endothelial cell adhesion molecule (PECAM), Tie-1, and Tie-2, the presence of Weibel-Palade bodies, and the capacity to incorporate acLDL $(39,40)$. The results showed that ECs-like derived from SKOV-3 or ES-2 can express Flk-1 or CD34, or vWF, form Weibel-Palade body-like organelles, and uptake acLDL. This study demonstrates that ECs-like derived from epithelial ovarian cancer cells present some similar endothelial-specific characteristics. Furthermore, Flk-1 appears to be the dominant signaling receptor in VEGFinduced mitogenesis, which is specifically expressed on ECs (41). The finding that ECs-like from both SKOV-3 and ES-2 express Flk-1 strongly implies the importance of Flk-1 in transendothelial differentiation as well.

The notion that tumors might contain 'cancer stem cells', rare cells with indefinite proliferative potential, that drive the differentiation and self-renewal provides new insights into cancer biology (42). The overall data suggest that CD34 and AC133 could be specific markers for various stem and progenitor cell populations, and CD $34^{+}$or/and $\mathrm{AC} 133^{+}$ cells from bone marrow as a subpopulation of cells could differentiate into ECs (43-45). The study showed that ECslike can express AC133 or CD34 after hypoxic deprivation, which suggested that these ECs-like might derive from ovarian cancer cells with stem cell characteristics, but further investigations are warranted to confirm this. Identification of the differences between endothelial precursor cells (EPCs) and mature ECs indicated that both cells may express some common endothelial-specific markers, including Flk-1, and $\mathrm{vWF}$, and they also have the capacity to incorporate ac-LDL (40). Partial marker expression of EPC can be lost or appear once the EPCs differentiate into more mature ECs, and AC133 is rarely found on mature ECs $(39,40)$. The present results demonstrate that ECs-like derived from epithelial ovarian cancer cells share similar characteristics with EPCs rather than ECs. This encourages further investigation into the potential relevance of a 'plastic' tumor-cell phenotype, and challenges our current knowledge of how to identify and target tumor cells that can masquerade as other cell types.

\section{Acknowledgments}

This study was supported by National Natural Science Foundation of China grants 30471806 and 30470689, Postdoctoral Science Foundation of China grant 20040350454, and Science and Technology Commission of Shanghai Municipality grant 04JC14021. This study used software developed by the Whitehead Institute for Biomedical Research.

\section{References}

1. Kerbel RS: Tumor angiogenesis: past, present and the near future. Carcinogenesis 21: 505-515, 2000.

2. Maniotis AJ, Folberg R, Hess A, Seftor EA, Gardner LM, Pe'er J, Trent JM, Meltzer PS and Hendrix MJ: Vascular channel formation by human melanoma cells in vivo and in vitro: vasculogenic mimicry. Am J Pathol 155: 739-752, 1999.

3. Folberg R, Hendrix MJC and Maniotis AJ: Vasculogenic mimicry and tumor angiogenesis. Am J Pathol 156: 361-381, 2000.

4. Sharma N, Seftor RE, Seftor EA, Gruman LM, Heidger PM Jr, Cohen MB, Lubaroff DM and Hendrix MJ: Prostatic tumor cell plasticity involves cooperative interactions of distinct phenotypic subpopulations: role in vasculogenic mimicry. Prostate 50: 189-201, 2002.

5. Shirakawa K, Kobayashi H, Heike Y, Kawamoto S, Brechbiel MW, Kasumi F, Iwanaga T, Konishi F, Terada M and Wakasugi $\mathrm{H}$ : Hemodynamics in vasculogenic mimicry and angiogenesis of inflammatory breast cancer xenograft. Cancer Res 62: 560-566, 2002.

6. Van Rompaey L, Holland E and Grosveld G: TEL induces aggregation in transformed cells and induces tube formation in NIH3T3-UCLA cells. Biochem Biophys Res Commun 291: 820-828, 2002.

7. Bariaga M: New type of blood vessel found in tumors. Science 285: 147, 1999.

8. Hendrix MJC, Seftor EA, Hess AR and Seftor REB: Vasculogenic mimicry and tumour-cell plasticity: lessons from melanoma. Nature 3: 411-421, 2003.

9. Kaufman B, Scharf O, Arbeit J, Ashcroft M, Brown JM, Bruick RK, Chapman JD, Evans SM, Giaccia AJ, Harris AL, Huang E, Johnson R, Kaelin W Jr, Koch CJ, Maxwell P, Mitchell J, Neckers L, Powis G, Rajendran J, Semenza GL, Simons J, Storkebaum E, Welch MJ, Whitelaw M, Melillo G and Ivy SP: Proceedings of the Oxygen Homeostasis/Hypoxia Meeting. Cancer Res 64: 3350-3356, 2004.

10. Kim WJ, Cho H, Lee SW, Kim YJ and Kim KW: Antisensethioredoxin inhibits angiogenesis via pVHL-mediated hypoxiainducible factor-1alpha degradation. Int J Oncol 26: 1049-1052, 2005 .

11. Knowles HJ and Harris AL: Hypoxia and oxidative stress in breast cancer. Hypoxia and tumourigenesis. Breast Cancer Res 3: 318-322, 2001

12. Zaffaroni N, Fiorentini G and De Giorgi U: Hyperthermia and hypoxia: new developments in anticancer chemotherapy. Eur J Surg Oncol 27: 340-342, 2001.

13. Hartmann A, Kunz M, Kostlin S, Gillitzer R, Toksoy A, Brocker EB and Klein CE: Hypoxia-induced up-regulation of angiogenin in human malignant melanoma. Cancer Res 59: 1578-1573, 1999.

14. Höpfl G, Wenger RH, Ziegler U, Stallmach T, Gardelle O, Achermann R, Wergin M, Kaser-Hotz B, Saunders HM, Williams KJ, Stratford IJ, Gassmann M and Desbaillets I: Rescue of hypoxia-inducible factor- $1 \alpha$-deficient tumor growth by wildtype cells is independent of vascular endothelial growth factor. Cancer Res 62: 2962-2970, 2002. 
15. Semenza GL: Hypoxia, clonal selection, and the role of HIF-1 in tumor progression. Crit Rev Biochem Mol Biol 35: 71-103, 2000.

16. Jiang Y, Xue ZH, Shen WZ, Du KM, Yan H, Yu Y, Peng ZG, Song MG, Tong JH, Chen Z, Huang Y, Lubbert M and Chen GQ: Desferrioxamine induces leukemic cell differentiation potentially by hypoxia-inducible factor-1 alpha that augments transcriptional activity of CCAAT/enhancer-binding protein-alpha. Leukemia 19: 1239-1247, 2005.

17. Jögi A, Ora I and Nilsson H: Hypoxia alters gene expression in human neuroblastoma cells toward an immature and neural crestlike phenotype. Proc Natl Acad Sci USA 99: 7021-7026, 2002.

18. Helczynska K, Kronblad Á, Jögi A, Nilsson E, Beckman S, Landberg G and Pahlman S: Hypoxia promotes a dedifferentiated phenotype in ductal breast carcinoma in situ. Cancer Res 63: 1441-1444, 2003

19. Yao LQ, Feng YJ, Ding JX, Xu CJ, Jin HY and Yin LH: Primary study of vasculogenic mimicry induced by hypoxia in epithelial ovarian carcinoma. Zhonghua Fu Chan Ke Za Zhi 40: 662-665, 2005.

20. Van der Schaft DW, Hillen F, Pauwels P, Kirschmann DA, Castermans K, Egbrink MG, Tran MG, Sciot R, Hauben E, Hogendoorn PC, Delattre O, Maxwell PH, Hendrix MJ and Griffioen AW: Tumor cell plasticity in Ewing sarcoma, an alternative circulatory system stimulated by hypoxia. Cancer Res 65: 11520-11528,2005.

21. Sun B, Zhang D, Zhang S, Zhang W, Guo H and Zhao X: Hypoxia influences vasculogenic mimicry channel formation and tumor invasion-related protein expression in melanoma. Cancer Lett, 2006 Sep 22 (Epub ahead of print).

22. Sood AK, Seftor EA, Fletcher MS, Gardner LM, Heidger PM, Buller RE, Seftor RE and Hendrix MJ: Molecular determination of ovarian cancer plasticity. Am J Pathol 158: 1279-1288, 2001.

23. Sood AK, Fletcher MS, Coffin JE, Yang M, Seftor EA Gruman LM, Gershenson DM and Hendrix MJ: Functional role of matrix metalloproteinases in ovarian tumor cell plasticity. Am J Obstet Gynecol 190: 899-909, 2004.

24. Hendrix MJC, Seftor REB, Seftor EA, Gruman LM, Lee LM, Nickoloff BJ, Miele L, Sheriff DD and Schatteman GC: Transendothelial function of human metastatic melanoma cells: role of the microenvironment in cell-fate determination. Cancer Res 62: $665-668,2002$

25. Levenberg S, Huang NF, Lavik E, Rogers AB, Itskovitz-Eldor J and Langer R: Differentiation of human embryonic stem cells on three-dimensional polymer scaffolds. Proc Natl Acad Sci USA 100: 12741-12746, 2003

26. Thompson SA, Johnson MP, Heidger PM Jr and Lubaroff DM: Characterization of the heterogeneity of R3327 rat prostatic tumors derived from single-cell clones. Prostate 6: 369-387, 1985.

27. Nagelkerke JF, Barto KP and van Berkel TJC: In vivo and in vitro uptake and degradation of acetylated low density lipoprotein by rat liver endothelial, kupffer, and parenchymal cells. J Biol Chem 258: 12221-12227, 1983

28. Brown JM and Giaccia AJ: The unique physiology of solid tumors: opportunities (and problems) for cancer therapy. Cancer Res 58: 1408-1416, 1998

29. Vaupel PW: The influence of tumor blood flow and microenvironmental factors on the efficacy of radiation, drugs and localized hyperthermia. Pediatrics 209: 243-249, 1997.

30. Blancher C, Moore JW, Robertson N and Harris AL: Effects of ras and von Hippel-Lindau (VHL) gene mutations on hypoxiainducible factor (HIF)- $1 \alpha$, HIF- $2 \alpha$, and vascular endothelial growth factor expression and their regulation by the phosphatidylinositol 3'-kinase/Akt signaling pathway. Cancer Res 61: 7349-7355, 2001.
31. Ye F, Chen HZ, Xie X, Ye DF, Lu WG and Ding ZM: Vascular endothelial growth factor (VEGF) and ovarian carcinoma cell supernatant activate signal transducers and activators of transcription (STATs) via VEGF receptor-2 (KDR) in human hemopoietic progenitor cells. Gynecol Oncol 94: 125-133, 2004.

32. Ferrara N: The role of vascular endothelial growth factor in pathological angiogenesis. Breast Cancer Res Treat 36: 127-137, 1995.

33. Cherrington, JM, Strawn LM and Shawver LK: New paradigms for the treatment of cancer: the role of anti-angiogenesis agents. Adv Cancer Res 79: 1-38, 2000.

34. Shen BQ, Lee DY, Gerber HP, Keyt BA, Ferrara N and Zioncheck TF: Homologous up-regulation of KDR/Flk-1 receptor expression by vascular endothelial growth factor in vitro. J Biol Chem 273: 29979-29985, 1998.

35. Mukhopadhyay D, Tsiokas L, Zhou XM, Foster D, Brugge JS and Sukhatme VP: Hypoxic induction of human vascular endothelial growth factor expression through c-Src activation. Nature 375: 577-581, 1995.

36. Ravi R, Mookerjee B, Bhujwalla ZM, Sutter CH, Artemov D, Zeng Q, Dillehay LE, Madan A, Semenza GL and Bedi A: Regulation of tumor angiogenesis by p53 induced degradation of hypoxia-inducible factor $1 \alpha$. Genes Dev 14: 34-44, 2000.

37. Kita Y, Masaki T, Funakoshi F, Yoshida S, Tanaka M, Kurokohchi K, Uchida N, Watanabe S, Matsumoto K and Kuriyama S: Expression of G1 phase-related cell cycle molecules in naturally developing hepatocellular carcinoma of Long-Evans Cinnamon rats. Int J Oncol 24: 1205-1211, 2004

38. Bos R, van Diest PJ, van der Groep P, Shvarts A, Greijer AE and van der Wall E: Expression of hypoxia-inducible factor-1 $\alpha$ and cell cycle proteins in invasive breast cancer are estrogen receptor related. Breast Cancer Res 6: 450-459, 2004

39. Gehling UM, Leyman ES, Schumacher U, Wagener C, Pantel K, Otte M, Schuch G, Schafhausen P, Mende T, Kilic N, Kluge K, Schafer B, Hossfeld DK and Fiedler W: In vitro differentiation of endothelial cells from AC133-positive progenitor cells. Blood 95: 3106-3112, 2000

40. Peichev M, Naiyer AJ, Pereira D, Zhu Z, Lane WJ, Williams M, Oz MC, Hicklin DJ, Witte L, More MA and Rafii S: Expression of VEGFR-2 and AC133 by circulating human CD341 cells identifies a population of functional endothelial precursors. Blood 95: 952-959, 2000.

41. Brekken RA, Overholser JP, Stastny VA, Waltenberger J, Minna JD and Thorpe PE: Selective inhibition of vascular endothelial growth factor (vegf) receptor 2 (kdr/flk-1) activity by a monoclonal anti-vegf antibody blocks tumor growth in mice. Cancer Res 60: 5117-5124, 2000.

42. Reya T, Morrison SJ, Clarke MF and Weissman IL: Stem cells, cancer, and cancer stem cells. Nature 414: 105-111, 2001.

43. Shmelkov SV, Jun L, McGarrigle D, Derderian CA, Usenko JK, Costa C, Zhang F, Guo X and Rafii S: Alternative promoters regulate transcription of the gene that encodes stem cell surface protein AC133. Blood 103: 2055-2061, 2004.

44. Asahara T and Kawamoto A: Endothelial progenitor cells for postnatal vasculogenesis. Am J Physiol Cell Physiol 287: C572-C579, 2004.

45. Yeh ETH, Zhang S, Wu HD, Körbling M, Willerson JW and Estrov Z: Transdifferentiation of human peripheral blood CD34+enriched cell population into cardiomyocytes, endothelial cells, and smooth muscle cells in vivo. Circulation 28: 2070-2073, 2003. 